\title{
"Yo soy aquel..." o la construcción del artista en el poema autorretrato modernista
}

\section{"Yo soy aquel..." or the construction of the artist in the modernist poem self-portrait}

Esnedy Aidé Zuluaga Hernández Universidad de Antioquia, Colombia esnedy@gmail.com

Resumen: El auge del poema autorretrato en el modernismo alcanzó con "Yo soy aquel..." de Darío el esplendor del "yo artista". Bajo este dominio del "yo", el poeta empieza a incorporar cada vez más elementos de su cotidianidad artística en el texto. Este trabajo explora ese "yo artista" a partir de "Yo soy aquel..." como poema paradigmático del modernismo, que se describe en función de su creación, de su capacidad para proponerse en el centro de la construcción poética, de la figura del artista como ese "otro" que se configura en el poema autorretrato y que logra convertirse en el centro de la composición en la que triunfa el "yo poeta" perpetuado en el poema.

Palabras clave: Rubén Darío, modernismo, poema autorretrato, poesía hispanoamericana, yo lírico. 
Abstract: In Modernism, the boom of the self-portrait poem got all the "artist I" splendor with "Yo soy aquel..." by Darío. Under this self-domain, the poet begins to bring in increasingly elements from his artistic daily life to the text. This search explores that "artist I" based on "Yo soy aquel..." as a paradigmatic poem of the Modernism who describes himself according to his creation, about his ability to propose oneself in the heart of the poetic creation and the figure of the artist as that other who takes shape in the self-portrait poem. The one who successes in becoming the composition center in which the "I poet" wins perpetuated on the poem.

Keywords: Rubén Darío, Modernism, Poem self-portrait, Spanish-American poetry, Poetic I lyrical.

Recibido: 1 de junio de 2019

Aceptado: 10 de septiembre de 2019 https://dx.doi.org/10.15174/rv.vi26.480

El Arte puro como Cristo exclama:

Ego sum lux et veritas et vita!

Rubén Darío, "Yo SOY AQUel..."

$\mathrm{Z}$ tanto que el poema autorretrato tiene como modelo al poeEta, la faceta de artista es una de las caras a las que atiende especialmente esta composición. El autorretrato puede incluir una sola pero a su vez decisiva alusión a su arte o varias alusiones que configuran completamente la composición, dominada por un "yo 
poeta”. ${ }^{1}$ Hablamos de la concepción del artista y su obra desde la figuración de sí mismo en el poema. Decirse poeta, sentirse poeta, verse poeta, encontrar en el arte el sentido de la existencia y la forma genuina de su expresión. Hablar de la génesis y el éxodo de su experiencia artística han sido algunos de los modos más recurrentes en los que el poeta pone de manifiesto su forma de concebirse como artista y de pensar la poesía desde el interior del texto.

En el modernismo, la figura autoral adquiere una importancia relevante como centro de la creación artística, que deriva en poemas autorretratos en los que el poeta se inventa a sí mismo en el contexto literario del poema. En estos términos, la intención de la autorrepresentación rebasa los límites de la descripción física e interna en la medida que crea una o más figuras autorales en constante interacción con el autor y su obra. Estamos hablando de la representación del "yo" en el autorretrato literario, en el or-

${ }^{1}$ Empleamos el "yo" (entre comillas) para hacer estricta referencia a la creación del sujeto o instancia textual por acción del poeta en el texto: el "yo del poema". Hacemos la aclaración por la indistinción natural que incluso hoy en pleno siglo XXI puede generar este tipo específico de poemas autorreferenciales a pesar de los trabajos que abundan al respecto, especialmente desde la teoría de la enunciación. Para este tema ver: Teoría del poema: la enunciación lírica (1998), coordinado por Fernando Cabo Aguinolaza y Germán Gullón, especialmente el estudio de Wahnón. Además Los lugares de la voz. Protocolos de la enunciación literaria (2000) de Laura Scarano. Adjetivamos el "yo" con un calificativo determinante en la composición: "yo artista", "yo poeta" o "yo creador" son los más empleados, porque hacen parte del campo semántico estudiado en este artículo. Aparecen además "yo sufriente", "yo del presente", "yo del pasado", entre otros definibles en el contexto específico de su utilización y que refieren a la caracterización de ese "yo" en el poema. Hay otros calificativos con un contexto histórico muy bien definido como el "yo sincero-sintiente", que tiene en el romanticismo la máxima expresión y puede entenderse en el modernismo como una categoría estética extremadamente útil en el estudio del poema autorretrato. 
den descriptivo, de lo verbal supeditado a la retórica que guarda una estrecha relación con el retrato pictórico. Especialmente en la poesía se proclamó la conquista de una individualidad declarada, la conciencia de sí mismo, el ser de artista que se exploró al máximo en el romanticismo, pero que fue fundado propiamente en el Renacimiento,

cuando las descripciones de seres humanos reales o imaginarios -que la retórica clásica consideraba como figuras de pensamiento, llamadas prosopografía o etopeya según se ocuparan de rasgos físicos o espirituales, respectivamente-, se erigen como un género literario que se concibe a sí mismo como variante verbal del retrato pictórico (González, 2013: 7).

Aunque bajo estas premisas el autorretrato como concepto parece ser un producto del Renacimiento, su práctica, en tanto posición del sujeto que se perfila a sí mismo en una constante indagación por su ser y por revelarse en el texto, es tan antigua como la poesía lírica y su vertiente más íntima. No obstante, es legítimo pensar que el poema como lugar de construcción del "yo artista", en el espacio de su propia escritura, fue una preocupación modernista que exploró ese "yo" artífice y dueño absoluto del texto, alcanzando su mayor y más fina expresión en el poema liminar de Cantos de vida y esperanza. Los cisnes y otros poemas (1905).

En este contexto, es imprescindible citar por los menos algunos de los primeros trabajos de María A. Salgado para darnos una idea de la importancia del poema autorretrato modernista en su producción académica: "Juan Ramón visto por Juan Ramón” (1981), "Perfil de Concha en sus autorretratos para oyentes" (1984), "Eco y Narciso: imágenes de Porfirio Barba Jacob" (1985), "Mirrors, Portraits, and the Self” (1986) y “El 'Autorretrato' de Rosario Castellanos: Reflexiones en torno a la feminidad y el arte de retratarse 
en México" (1988). Aunque sus trabajos no se dedican en extenso a discutir el concepto de autorretrato, explora en detalle sus peculiaridades de acuerdo a la época (especialmente en el modernismo) y a las especificidades de cada poeta a partir de la definición que propone y que va modelando a lo largo de su producción.

Salgado afirma, desde sus primeros estudios y ratifica en no pocas ocasiones, que es esencial "que se establezca explícitamente que el autor es el referente externo del yo" (1989: 393). Su definición "acoge solo aquellos textos en los que el autor se identifica explícitamente como el referente histórico de la voz poética” (1995: 213214). Más allá de la idea de que un poema "pueda ser leído como autorretrato", ${ }^{2}$ entendemos el énfasis de Salgado y su referencia a un pacto entre el autor y el lector a modo de Philippe Lejeune: ${ }^{3}$

El término autorretrato (contrario a la autobiografía -la narración de toda una vida) designa, a mi entender, un texto corto (análogo al retrato pictórico) en el que el autor delinea una o varias facetas de su persona, admitiendo explícitamente ser el referente extratextual de la "persona" o protagonista del texto" (1988: 71).

En estos términos, el poema autorretrato liminar de Cantos, objeto de estudio en función de la creación de un "yo artista", tiene por lo menos dos antecedentes importantes en la etapa fundacional del modernismo: "Autobiografía” de Julián del Casal (1863-1893)

${ }^{2}$ Esta apreciación de Salgado nos recuerda a Paul de Man (1919-1983): "La autobiografía no es un género o un modo, sino una figura de lectura y de entendimiento que se da, hasta cierto punto, en todo texto" (114).

${ }^{3}$ Tema estudiado en extenso en su libro Le pacte autobiographi (1975), principalmente en el primer capítulo (13-46) que expone los planteamientos generales del pacto. 
y "Yo soy un hombre sincero" de José Martí (1853-1895). ${ }^{4}$ Ambos poemas abren Hojas al viento (1890) y Versos sencillos (1891), respectivamente.

Además es imprescindible mencionar "Adelfos" de Manuel Machado (1874-1947), fechado en París en 1898, que inaugura Alma (1902). Siguiendo el mismo modelo, el poeta abre con otros dos autorretratos su libro El mal poeta (1909): "Retrato" y "PrólogoEpílogo", poemas introductorios a la obra o, mejor, a la imagen del poeta que construye el autor ("Yo poeta decadente" sigue la misma línea). Heredero de esta tradición, su hermano Antonio Machado (1875-1939) abre su libro Campos de Castilla (1912) con "Retrato". Estos trabajos liminares siguen la misma práctica de poema invitación, introductorio a la obra o, en el caso del autorretrato, a la persona, respondiendo al tópico del poeta que el lector tiene en sus manos.

Desde el título del poema del Casal evidenciamos la pretensión autobiográfica de la composición y, aunque realmente es el segundo poema del libro, posterior a "Introducción", la ubicación en el texto está en concordancia con el sentido preliminar de presentación. Así lo confirman sus primeros versos. Se reconoce en su país "como una afirmación de orgullo nacional del poeta, hecha cuando en su isla natal conspiraba el criollo contra el régimen colonial español, para conquistar la nación independiente que habían logrado ante los demás pueblos latinoamericanos" (Augier, 2007: XXII-XXIII). Este reconocimiento introduce la firmeza de un "yo" que pasa altivo y plácido por la vida: "Nací en Cuba. El sendero de la vida / firme atravieso, con ligero paso" (del Casal, 2007: 6).

${ }^{4}$ En "Autorretrato y mitificación de José Martî", Alfonso García Morales estudia el poema liminar de Versos sencillos (1891) como autorretrato ejemplar de un "yo heroico" en el que Martí creó su imagen mitificada (2009: 163-174). 
Pero más que narrar su vida, del Casal perfila a un hombre de fuerte carácter pesimista, ${ }^{5}$ agobiado por un mundo que nada le ofrece. La soledad y la muerte que acompañaron sus primeros años lo hacen llegar moribundo a una juventud que contempla mediante un desdoblamiento para intensificar a ese "yo sufriente". Una doble presencia tiene lugar, la del "yo" que se describe agobiado y la de su juventud personificada de "semblante cadavérico", a la que trata de resucitar el "yo":

Mi juventud, herida ya de muerte,

empieza a agonizar entre mis brazos, sin que la puedan reanimar mis besos, sin que la puedan consolar mis cantos (2007: 6-7).

En estos términos la palabra "cantos" se entiende con el genérico de arte. Frente al sinsentido de una vida atormentada por la soledad y el abandono de los primeros ańos, que desemboca en una juventud devastada, el "yo" se regocija en el arte como mecanismo de defensa:
Para olvidar entonces las tristezas
que, como nube de voraces pájaros
al fruto de oro entre las verdes ramas,
dejan mi corazón despedazado,

\begin{abstract}
${ }^{5}$ Ángel Augier señaló que "esa actitud negativa de indudable condición patológica" es producto de una "orfandad prematura" que "influyó decisivamente en su compleja psicología", sumada a la efervescencia política de la independencia cubana que apenas estaba por concretarse. En este contexto, "Autobiografía" "hace alusión en forma simbólica a la orfandad, punto de partida de su infortunio vitalicio" (Augier, 2007: XXII). Casal y Darío comparten esa experiencia de orfandad. Desde los nueve años Casal quedó a cargo de un internado religioso dado que su madre murió cuando apenas tenía cinco años (Augier, 2007: X-XI). Por otro lado, Darío es abandonado por sus padres y educado por la familia de un tío.
\end{abstract}


refúgiome del Arte en los misterios

o de la hermosa Aspasia entre los brazos (2007: 6-7).

Aunque el tema del arte apenas está enunciado es el punto de quiebre del poema, el momento que el "yo" retorna de esa oscuridad para encontrarse en su deseo de vivir y no dejarse llevar por sus tristezas. El desencanto cifrado en el abandono y la proximidad a la muerte toman otro sentido: el camino iluminado por el arte que le permite al "yo" ver el porvenir a pesar de todo el desencanto que se teje en el poema. Y es precisamente en esa mención al arte como refugio que la voz da un giro bajo la estructura de nueve estrofas; justo en el centro de la composición está la referencia clave.

De forma análoga en Martí, el asunto del "yo artista”, sin ser un asunto menor, no es el más destacado, aunque ocupa un lugar importante en la composición como en el caso del autorretrato de del Casal. En "Yo soy un hombre sincero" el arte está en el núcleo de la definición del "yo" que echa sus versos del alma para dar cuenta del mundo que pasa ante sus ojos, el que piensa y presencia desde un movimiento que no cesa. El mismo elemento con el que empieza el poema de del Casal, un moverse lentamente como recurso de la memoria que también es empleado por Martí. El "yo" que contempla al mundo parece crearlo en tanto recuerda lo visto. Un canto a la vida del poeta que ha vivido y presencia la experiencia de vivir de los otros con toda atención. Martí da cuenta de ese "doble lugar estético" donde se piensa el poeta modernista:

Yo vengo de todas partes,

Y hacia todas partes voy:

Arte soy entre las artes,

En los montes, monte soy"

[...]

Yo he visto en la noche oscura 
Llover sobre mi cabeza

[...]

Alas nacer vi en los hombros

De las mujeres hermosas:

[...]

He visto vivir a un hombre

Con el puñal al costado (1997:16).

Martí perfila a un hombre andariego, sensible ante los acontecimientos elementales de la vida, preocupado por el acontecer del afuera mediante el que se describe indirectamente a sí mismo. El arte de contar lo define, y por medio de la utilización de octosílabos propios de la copla criolla se emparenta con la expresión artística del trovador, que lo acerca al sentir y al hacer popular al que tanto quiso llegar con su gran sueńo de la independencia cubana. Un buen ejemplo del realismo y el naturalismo que también influyeron en el modernismo como lo señaló Max Henríquez Ureña $(1886-1968){ }^{6}$

En el caso de "Adelfos" la breve referencia al arte aparece en el tercer verso de la quinta cuarteta: "Un vago afán de arte tuve... Ya lo he perdido / Ni el vicio me seduce, ni adoro la virtud" (2003: 47). Después de reconocerse en su descendencia árabe el "yo" se

\begin{abstract}
${ }^{6}$ A mediados del siglo xIx aparecieron en Europa diferentes tendencias literarias que se opusieron a los excesos del romanticismo. En este ambiente de renovación, bajo la influencia de las escuelas francesas y el alejamiento de las fuentes literarias espańolas, aparece el modernismo. El parnasianismo y su culto a la forma, el simbolismo y la renovación del verso y el romanticismo, con la expresión individual de un "yo sintiente", lo determinaron. Y como lo dijo Henríquez Ureña el realismo, el naturalismo y el impresionismo también tuvieron cabida (1962: 12); esto puede rastrearse en la preocupación por la vida cotidiana, la intención de reproducir objetivamente la realidad, el regreso a una naturaleza interiorizada, refinada y mística, además en el hecho de que en muchas ocasiones antes que hablar de las cosas el modernista recurrió a sus múltiples impresiones.
\end{abstract}


expresa en un tono desencantado y por momentos de profunda insatisfacción. En este orden de ideas su arte, la poesía, a pesar de que ocupa un lugar central en la composición en relación con la ubicación, como en el caso de los dos poemas antes citados, no es un elemento que destaque de manera especial, simplemente se suma a la lista de decepciones. A la voluntad muerta, sin ilusiones, sin ambición y sin amor está la pérdida del "vago afán de arte".

A diferencia de del Casal y Martí, y aún más de Manuel Machado, en Darío la faceta del poeta domina completamente el texto. El "yo artista” se reconoce en su creación poética, dotado del protagonismo que potencia el lugar privilegiado del poema liminar. "Yo soy aquel..." es una propuesta estructurada sobre la base de un "yo poeta" que se expone como artista y supedita el escenario del poema en el que opera. El arte ya no es solo un consuelo como en del Casal, ahora es la razón de ser, el "yo poeta” es la faceta del retrato que Darío explota y la sinceridad se convierte en un artificio finamente calculado para lograr que ese efecto se le adjudique sin más al poeta de carne y hueso, porque ahora se vuelve decisiva la apariencia de ser, de convencer al lector de lo sincero que es el poeta y de la transparencia de esa voz del poema en la que está el sentimiento vivo de Darío.

Pero en "yo soy aquel..." no solo hay un artista que se reconoce en su obra sino un poeta que, desde el primer verso en una proyección "yo / aquel" en la que funda su presente, se piensa en un espacio donde abundan las referencias a la poesía. El decir de "aquel" señala los dos libros de Darío, los adjetivos calificativos ("azul” y "profana") construyen la referencia a dos momentos estéticos cumbres de su obra. Azul... (1888): la escritura en prosa en la que se reconoció el modernismo bajo una fuerte influencia francesa, la concreción del primer triunfo de un Darío que apenas superaba 
los veinte años de edad. ${ }^{7}$ En Prosas profanas y otros poemas (1896) alcanzó su plenitud estética en la forma preciosista, cumbre y cierre de esta primera etapa que motivó la conocida crítica de José Enrique Rodó (1971-1917); y que a su vez determinó el carácter de Cantos y más especialmente del poema liminar que nos ocupa.

El poeta se presenta ante el lector como escritor consagrado bajo la disyuntiva ("yo" / "aquel") que apela al reconocimiento de sus libros mediante esta sugerencia fácilmente identificable. El escritor maduro de Cantos se ve en el joven Darío de Azul... y Prosas. El "yo del presente" se reconoce en el "yo del pasado" desde la referencia de las obras que lo respaldan, los libros publicados son su gran baluarte. De esta forma el poema autorretrato se concentra en la faceta escritural de Darío, la que se propone retratar y la que es motivo de la ambiciosa propuesta literaria. Es la figura del escritor la que exhibe el autorretrato, el "yo poeta" se despliega desde la posibilidad literaria de ser en el poema el artista que Darío es y el que imagina ser. En la alusión poética a sus dos libros de poesía, no a sus otros libros publicados para la fecha, se configura el espacio autobiográfico de ese otro "yo poeta":

7 Darío escribió "Yo soy aquel..." ya consolidado como uno de los poetas más importantes de su época. El poema se publicó primero en la revista Alma española en 1904. Considerado un nińo prodigio por sus dotes literarias, publicó en Chile, a sus apenas veinte años, su primer libro de poemas titulado Los abrojos (1887), seguido de $A z u l . .$. (1888). Este segundo libro que también publicó en Chile mereció la atención de Juan Valera, un reconocido escritor español que publicó el 22 y el 29 de octubre de 1888 dos cartas en El Imparcial de Madrid referenciando su obra, luego consignadas en Cartas americanas (1888). Después de $A z u l$ publicó la obra que mayor atención suscitó: Prosas profanas y otros poemas (Buenos Aires, 1896), que mereció el extenso estudio que Rodó le dedicó y que encabezaría a modo de prólogo la segunda edición ampliada y publicada en París en 1901. Como antesala a la escritura de "Yo soy aquel...", Darío contaba con más de una docena de libros publicados en varios países y mantenía relaciones intelectuales con los escritores hispanoamericanos más importantes del momento. 
Yo soy aquel que ayer no más decía el verso azul y la canción profana, en cuya noche un ruiseñor había que era alondra azul por la mañana (1977: 244).

El "yo" del presente se afirma en el "otro" ("aquel”) del pasado determinado por la escritura. En este reconocimiento del "yo" en "otro yo" hay una marcación temporal que se metaforiza en un espacio dado por los pares noche-día / oscuridad-luz, en los que anida el pájaro (el canto, la poesía). En la noche el ruiseñor y en el día la alondra, el canto llenando la totalidad del espacio. El primero, el pájaro más celebrado por su improvisación, la variedad de inflexiones y la duración de su canto que se intensifica en la primavera, ${ }^{8}$ estación anunciada precisamente por la alondra (Paula, 1851: 208). El canto de la alondra es un indicador de la luz, canta con los primeros rayos del sol, suspende su canto al mediodía (momento de mayor y más intensa luminosidad) y retoma el canto en el descenso del sol. Enmudece en momentos de oscuridad y lluvia y canta siempre que hay buen tiempo (Paula, 1851: 209).

En este espacio determinado por el canto se reconoce el "yo poeta”. La poesía es el telón de fondo de la figura de poeta que perfila Darío en un ciclo de luz y oscuridad en el que no cesa el canto. El poeta es "dueño" de su "jardín de ensueño", de "las rosas", "los cisnes vagos", "las tórtolas", de las "góndolas y liras en los lagos" (1977: 244). El dominio del "yo" está limitado por el espacio literario donde se presenta el jardín sońado, imaginado, pensado, concretado en su poesía. La música se intensifica en la escena con el canto de los pájaros, el sonido de la lira y del agua. Todos los

8 "Cantan de noche lo mismo que de día, y aun con más ardor y con más frecuencia, lo que quizás será efecto del silencio y soledad de la noche” (Daubenton, 1788: 340). 
elementos armónicamente dispuestos en la estrofa contrastan con el cisne, símbolo por excelencia del modernismo. Pero calificarlo con un adjetivo que remite a la vaguedad, a lo indefinido, rompe con su imagen espléndida e imperturbable. ${ }^{9}$ Esta idea ya había sido introducida al final de Prosas: "y el cuello del gran cisne blanco que me interroga” (1977: 241). En un ejercicio de introspección, Darío se cuestiona bajo el símbolo por excelencia de su poesía y a su vez del sentido que alberga en su obra: ya no es el cisne el centro de la composición, es él como figura protagónica del poema y el cisne un ornato más.

En este percatarse por el lugar de su "yo artista”, Darío se reconoce en dos de las corrientes literarias que determinaron el modernismo: el romanticismo en Víctor Hugo (1802-1885) y el simbolismo en Paul Verlaine (1844-1896). Estamos ante dos corrientes antagónicas, en tanto que la segunda se crea en un ambiente generalizado de oposición a la primera. Nuevamente las referencias literarias son las que establecen ese "yo poeta" en construcción. Cabe destacar una referencia importante que aparece a modo de confirmación al final del poema "La canción de los pinos", escrito en 1907:

Románticos somos... ¿Quién que Es, no es romántico?

Aquel que no sienta ni amor ni dolor, aquel que no sepa de beso y de cántico, [...]

¡Yo soy el amante de ensueños y formas que viene de lejos y va al porvenir! (1977: 335).

${ }^{9}$ El cisne es el animal de Darío, en él cifra todo el potencial de su poesía. Su elegancia y refinamiento han sido expuestos en muchos de sus poemas: "ebúrneo cisne" (1977: 182), "los cisnes unánimes en el lago azur" (187), "olímpico cisne de nieve” (188), “cisne, de estirpe sagrada” (188), “dioses” (189), “ ¡Oh Cisne! ¡Oh sacro pájaro!” (213). 
Darío nunca dejó de sentirse un romántico, como no lo hizo ninguno de los modernistas, a pesar de las evidentes influencias posrománticas que también los determinaron. El modernismo bebió especialmente de las fuentes francesas. En este conocimiento de las corrientes literarias en boga, Darío se reconoció moderno; pero no solamente siguió influenciado por el romanticismo sino que a su vez retomó figuras, conceptos y vocabulario del neoclásico, dándole un carácter antiguo a esa declaración de la génesis de su poética, que se contrapone a la idea declarada de poesía de los nuevos tiempos, de la urbe: "y muy siglo diez y ocho y muy antiguo / y muy moderno; audaz, cosmopolita” (1977: 244).

Darío empezó en las letras bajo esa transición del neoclasicismo al romanticismo (Soto, 1967: 466). Los referentes de la antigüedad clásica abundan en su poesía y el autorretrato que nos ocupa es un buen ejemplo de estas inclusiones, que también tienen su origen en el parnasianismo; sin embargo, conforme al poema, seguimos la pista del siglo XVIII para anotar la intensión de Darío de referir la influencia del neoclásico en su poesía. La figura que finalmente termina por modelar el autorretrato es una estatua grandilocuente que, contrario a la pose fría y estática que caracterizaría al neoclásico, está dotada de particularidades románticas, como el sentimiento, la pasión, el movimiento, los contrastes, los arrebatos de la naturaleza salvaje y mitológica. Hay una estatua, pero es de carne, lo dice el poema bajo aclaración de atribuirle el mármol.

Esta configuración en escenas fotográficas con movimientos congelados responde al mejor estilo del arte neoclásico. La correlación de la figuración del "yo" con una estatua es explícita y el hecho de ser de "carne viva" le da cierta movilidad a un escenario de tres espacios conjugados: el jardín, el bosque y la selva. El jardín es el lugar primero y ornamental donde aparece la estatua y donde ocurre su transformación. La estatua se equipara con el orden mí- 
tico bajo la imagen de Pan, dios silvestre de aspecto salvaje mitad cabra y mitad humano:

que a la estatua nacían de repente

en el muslo viril patas de chivo

y dos cuernos de sátiro en la frente (1977: 245).

Acá la juventud de Darío, "la plasmación lírica de la vida se realiza a fogonazos, desarticuladamente, en un orden más complejo y connotado que el meramente lógico" (Muñoz, 2000: 167). Porque lo importante no es lo que le aconteció en su niñez, sino dejar esa impresión dolorosa, tampoco el detalle de lo que fue su juventud, sino reconstruir esa pasión de los años encauzados por la música de la dulzaina del Pan griego, elementos que fueron tan influyentes en su vida artística. Darío juega con sus recuerdos y, expresado en términos de Paul de Man: los desfigura necesariamente como proceso de su elaboración literaria, porque finalmente lo que hace Darío es emplear esos elementos de la memoria que dan cuenta del poeta que se yergue en el texto, que se encarna en la estatua y le da un carácter sensual, salvaje y libertino a la construcción del retrato que pretende (de Man, 1991: 113-118). Esta escena plástica que acontece en el jardín se extiende a los límites del bosque, donde continúa la escenificación literaria de "la estatua bella":

Bosque ideal que lo real complica, Allí el cuerpo arde y vive y Psiquis vuela;

mientras abajo el sátiro fornica, ebria de azul deslíe Filomena (1977: 246).

El jardín se extiende al bosque, ambos lugares contribuyen a la construcción del plano de la invención en el poema, por eso estos espacios se conjugan para incrementar el dramatismo de la escena 
que propone Darío. Estamos ante un orden corporal, del goce de la carne. Psiquis en el aire, el sátiro fornicando en la tierra, Filomena perdiéndose en el cielo seguramente ya convertida en ruiseñor, Hipsípila bebiendo la miel de las rosas mientras un fauno pícaro muerde un pezón, el dios persiguiendo a la hembra y la música de fondo que no cesa. En el escenario la estatua ocupa el primer plano ante este derroche erótico que protagoniza el "yo poeta". Esta construcción bien puede leerse a la luz de las pinturas del neoclásico: $E l$ parnaso (1761) de Mengs es un buen ejemplo de esta escenificación.

En contraste con el jardín y el bosque, la selva se corresponde con un orden espiritual más amplio que los contiene. La selva es el gran referente de realidad en el poema, la posibilidad de entender esa teatralidad del "yo". Hay en ella una estructura más compleja y propositiva, lugar de recogimiento que acopla armónicamente el alma y el cuerpo. La "selva sagrada” es la racionalización de la hecatombe y el desenfreno del sentir, de las sensaciones extremas e instintivas experimentadas en la juventud ${ }^{10}$ que encuentran sosiego en Dios y en el Arte, dos expresiones de un mismo orden sagrado que pretende la salvación del hombre mediante la religión y la vida artística, la religión del arte o la selva como referente.

Ángel Rama (1926-1983) afirma que Darío, a diferencia de Martí, "decidió conservar a Dios", lo que lo llevó a la concepción de la "selva sagrada", símbolo de la fuerza de la naturaleza americana (1977: XXX). "La selva se ha redimensionado y ya no se opone al mundo sino que lo abarca”, "es lo real, es el universo de la materia y de las construcciones que con ella hace el hombre, pero emana del espíritu divino, por lo cual, partiendo de lo uno, estatuye lo múltiple contradictorio" (Rama, 1977: XXXIII). La selva, por tanto, no solo tiene márgenes más amplias que el bosque y

${ }^{10}$ La juventud y la niñez retratadas están mediadas por la melancolía: la niñez más cercana al dolor y la juventud al desenfreno. 
el jardín sino que son indefinidas e inabarcables y en esos límites difusos está su misterio.

Este triple espacio define el carácter del “yo”. En principio la serenidad y el control del jardín quedan opacados por la sensualidad del bosque que aparece en los límites del misterio de la selva. En un escenario grandilocuente y etéreo, armonizado por la música de la flauta y la lira que se acentúa al final, ${ }^{11}$ se yergue la presencia altiva del "yo". A este sonido que acompańa el retrato de Darío, primero el canto del ruiseñor y la alondra y ahora la música de la flauta y de la lira, se suma el azul próximo a la oscuridad para recrear la inmensidad inspiradora del cielo:

Del crepúsculo azul que da la pauta

que los celestes éxtasis inspira, bruma y tono menor - itoda la flauta!, y Aurora, hija del Sol — itoda la lira!" (1977: 247).

El color y el sonido se conjugan para dar paso a la estatua que pasa incólume y altiva exhibiendo el triunfo absoluto del "yo poeta" en el texto. A pesar de los embates de la existencia se mantiene en pie por la fuerza y gracia del arte en el que permanece firme y decidido.

La virtud está en ser tranquilo y fuerte; con el fuego interior todo se abrasa; se triunfa del rencor y de la muerte, y hacia Belén... ¡la carava pasa! (1977: 247). ${ }^{12}$

${ }^{11}$ Más cerca de la lira, que históricamente fue el instrumento que los poetas tocaban mientras recitaban o entonaban sus poemas. Rememorando los tiempos primigenios en los que la poesía y la música estaban fusionadas en una sola expresión artística que incluía la puesta en escena del poema.

${ }^{12}$ La caravana pasa (1902) es un libro de crónicas de Darío, poco conocido. La mayor parte de las crónicas son escritas en París y publicadas en La Nación de 
Darío se vale de la impresión del color, el sonido, las formas y el movimiento para crear una atmósfera brumosa y solemne en la que transita exquisita la estatua que ha tenido una presencia escultórica y mitológica en el poema. Textualmente no está desfilando en una refinada procesión en la que se pontifica, pero sí hay una propuesta de carácter impresionista que la sugiere. El poema perfila a un hombre que no puede ser más que un artista engrandecido en y por el arte, pero un arte sacralizado en el poder de la selva americana que continúa su camino en la medida que la caravana lo lleva a Belén, el lugar sagrado por excelencia del cristianismo, destino de las peregrinaciones religiosas. Esta caravana está conectada con las referencias a Dios que son el complemento del arte conjugado en la selva. Ambas presencias en el poema son la expresión del regocijo del "yo", de su salvación espiritual y material:

Mas, por gracia de Dios, en mi conciencia

el Bien supo elegir la mejor parte;

y si hubo áspera hiel en mi existencia, melificó toda acritud el Arte (1977: 245).

$[\ldots]$

El Arte puro como Cristo exclama:

Ego sum lux et veritas et vita! (246).

El Arte, Dios y la Selva son la misma expresión mayúscula de un orden superior en el que el "yo" se reconoce como poeta, creador y redentor de un mundo que domina y del que sale triunfante, porque todo lo que acontece en el universo textual está calculado para ese momento. Después de los elementos míticos que circun-

Buenos Aires entre 1901 y 1902. El título de su libro proviene de un proverbio árabe ("Los perros ladran; la caravana pasa") que parece no tener una relación directa con sus crónicas. 
dan la estatua la escena alcanza una serenidad que remite a un famoso proverbio árabe del que solo aparece la segunda parte en el poema, porque lo importante no es que ladren los perros, sino que la caravana pase. Ahí va Darío encabezando la comitiva o, mejor, va la espléndida estatua que levantó y transformó en los límites de un jardín que la selva modeló a imagen y semejanza del ser americano. El "yo del presente" retrata al "yo del pasado" para consolidar el "yo del porvenir" que sigue la dirección del triunfo del poeta por el arte. A la génesis de su poesía en los albores pasionales de su juventud le sigue el éxodo definitivo de su consagración, que fue posible gracias a ese "yo" que miraba a su pasado para erguirse en el futuro.

Mediante el autorretrato, el poeta modernista se pensó y se conoció a sí mismo (por lo menos dio cuenta de ese proyecto) desde su especial condición de artista, para hacer frente a los conflictos de su propia creación y de las críticas de sus pares a su obra y a su persona. De modo que el autorretrato responde a una conciencia histórica mediante la cual el poeta busca dejar un registro. En este punto entra en resonancia con la autobiografía que, como lo recuerda Jean-Philippe Miraux, es el procedimiento mediante el cual el escritor es el objeto de estudio de su propia obra (2005: 9).

Si bien el autorretrato y la autobiografía distan teóricamente, pues el primero tiene un carácter de estampa, de condición estática, de tiempo y espacio breves, la segunda es la narración de una vida en términos cinematográficos y dinámicos; sin embargo, hay una conexión innegable que habría que pensar mejor, motivados por la construcción móvil del "yo" del poema de Darío y de la consideración de Miraux cuando afirma que la autobiografía "es tensión hacia la significación, intento de edificar un monumento armónico basado en elementos inconexos, abigarrados y variados de una vida” (37). Este proceso, que bien puede describir el carácter del autorretrato literario en su estatus segmentado e instantá- 
neo, le permite al poeta modernista convertir su propia persona en motivo central de la composición.

Si en el romanticismo la expresión del "yo sincero-sintiente" llegó a ser hostigante, el modernismo hizo uso de la individualidad desbordada y de la construcción de una subjetividad delirante para potenciar la figura del artista, que configuró el poema autorretrato como escenario dominado por el perfil de un "yo creador", determinado por parámetros pictóricos, pero que no entran en estricto conflicto con un modelo autobiográfico, que no solo está interesado en narrar los hechos como un todo sino que lo hace desde uno o varios segmentos de una vida, atendiendo a un razonamiento consiente de lo vivido.

\section{Bibliografía}

Augier, Ángel, 2007, “Prólogo: Julián del Casal en el contexto del modernismo hispanoamericano", en Julián del Casal, Páginas de vida, poesía y prosa, Fundación Biblioteca Ayacucho, Caracas, pp. IX-XLVIII.

Casal, Julián del, 2007, Páginas de vida, poesía y prosa, Ángel Augier (comp.), Fundación Biblioteca Ayacucho, Caracas.

Darío, Rubén, 1977, Poesía, Ernesto Mejía Sánchez (ed.), Fundación Biblioteca Ayacucho, Caracas.

, 1917, La caravana pasa, Editorial Mundo Latino, Madrid.

Daubenton, Louis Jean Marie, 1788, Encyclopedia Metodica. Historia natural de las aves, t. II, Joseph Mallent (trad.), Antonio de Sancha, Madrid.

García Morales, Alfonso, 2009, “'De donde crece la palma'. Autorretrato y mitificación de José Martî”, Eugenia Houvenaghel y 
Ilse Logie (edit.), en Alianzas entre historia y ficción: homenaje a Patrick Collard, Editorial Droz, Ginebra.

González Arce, Teresa, 2013, Triunfar de la vejez y del olvido, Arlequín, México.

Henríquez Ureña, Max, 1962, Breve historia del modernismo, Fondo de Cultura Económica, México.

Machado, Manuel, 2003, Antología poética, Manuel Márquez de la Plata (ed.), Biblioteca Edaf, Madrid.

Man, Paul de, 1991, "La autobiografía como desfiguración”, en La autobiografía y sus problemas teóricos. Estudios e investigación documental. Suplementos Anthropos, núm. 29, pp. 113-118.

Martí, José, 1997, Versos sencillos. Simples Verses, Recovering the U.S. Hispanic Literary Heritage. Arte Pública Press, Texas.

Mengs, Anton Raphael, 1761, El parnaso, Fresco, Galería de Villa Albani-Torlonia, Roma.

Miraux, Jean-Philippe, 2005, La autobiografía. Las escrituras del yo, Nueva Visión, Buenos Aires.

Muñoz Carrasco, Olga, 2000, "La vida de Rubén Darío cantada por el mismo: poesía como autobiografía", Anales de literatura hispanoamericana, núm. 29, pp. 165-177.

Paula Mellado, Francisco de, 1851, Enciclopedia moderna. Tomo segundo. Diccionario Universal, Establecimiento tipográfico de Mellado, Madrid.

Philippe, Lejeune, 1975, Le pacte autobiographique, Seuil, París.

Salgado, María A, 1988, “El 'Autorretrato’ de Rosario Castellanos: reflexiones sobre la feminidad y el arte de retratarse", Letras femeninas, vol. 14, núms. 1-2, pp. 64-72.

, 1989, "En torno a los modernistas y las autosemblanzas de El Liberal", Actas del IX Congreso de la Asociación Internacional 
de Hispanistas 18-23 agosto 1986 Berlín, vol. 2, Vervuert, pp. 389-396.

, 1995, "De lo jocoso a lo jocoso-serio: el autorretrato literario en los Siglos de Oro y la Ilustración”, Actas del XII Congreso de la Asociación Internacional de Hispanistas, pp. 212-220. Soto Vergés, Rafael, 1967, "Rubén Darío y el neoclasicismo: La estética de lo "abrojos", Cuadernos Hispanoamericanos, núms. 212-213, pp. 462-471.

Rama, Ángel, 1977, "Prologo", Rubén Darío, en Poesía, Ernesto Mejía Sánchez (ed.), Fundación Biblioteca Ayacucho, Caracas, pp. IX-LII. 